\title{
ESTUDANTES PÚBLICO-ALVO DA EDUCAÇÃO ESPECIAL NOS INSTITUTOS FEDERAIS: QUEM SÃO?
}

\author{
Target Students of Special Education in the Federal Institutes: Who are They?
}

\author{
Wanessa Moreira de Oliveira ${ }^{1}$ \\ Cristina Maria Carvalho Delou ${ }^{2}$
}

\begin{abstract}
Resumo: Considerando a inexistência de um Censo Escolar específico da Educação Profissional e Tecnológica que abarque os Institutos Federais de Educação, Ciência e Tecnologia (IFs) e que a recente Plataforma Nilo Peçanha, apesar de reunir várias informações dos IFs, ainda não esboce dados dos estudantes público-alvo da Educação Especial (EE), tornase necessário ressaltar a importância de tais informações para a avaliação das políticas educacionais. Nesse sentido, o presente estudo objetiva identificar e analisar os dados, de acesso público, sobre o ingresso e permanência de estudantes público-alvo da EE nos IFs no período de 2015 a 2019. Trata-se de uma pesquisa exploratória de abordagem qualitativa, na qual foram buscadas informações para identificar e caracterizar os estudantes público-alvo da EE em todos os 38 IFs do país, por meio do Sistema Eletrônico do Serviço de Informação ao Cidadão do Governo Federal. Os dados coletados foram explorados por meio da análise de conteúdo, a qual possibilitou constatar que os IFs, de modo geral, dispõem de dados pouco organizados sobre os estudantes público-alvo da EE, utilizam-se de nomenclaturas pouco padronizadas e têm ampliado o público-alvo da política de inclusão, definida em legislação. Observou-se ainda que tais estudantes apresentam, em sua maioria (69\%), deficiência física, visual, ou auditiva, e representam uma parcela muito pequena da comunidade estudantil. Apesar das limitações, o trabalho empreendido evidencia questões importantes para pesquisas futuras e pode contribuir para demonstrar a importância dos dados sobre os estudantes público-alvo da EE para melhoria das políticas de inclusão escolar, especialmente nos IFs.
\end{abstract}

Palavras-chave: Educação Profissional e Tecnológica. Educação Inclusiva. Censo Escolar.

Abstract: Considering the lack of a specific School Census of Professional and Technological Education that contemplates the Federal Institutes of Education, Science and Technology (FI) and that the recent Nilo Peçanha Platform, despite gathering various information from the FIs, does not yet outline data of target students of Special Education (SE), it is necessary to emphasize the importance of such information for the evaluation of educational policies. In this sense, the present study aims to identify and analyze data with public access about the admission

\footnotetext{
1 Doutoranda no Programa de Pós-Graduação em Ensino em Biociências e Saúde do Instituto Oswaldo Cruz/FIOCRUZ; Mestre em Diversidade e Inclusão pela Universidade Federal Fluminense; Assistente Social no IF Sudeste/MG. https://orcid.org/0000-0002-8679-3296. E-mail: oliverwanessa85@gmail.com.

2 Doutora em Educação pela Pontifícia Universidade Católica de São Paulo; Mestre em Educação pela Universidade do Estado do Rio de Janeiro; Psicóloga; professora aposentada da Faculdade de Educação da Universidade Federal Fluminense; professora colaboradora no Programa de Pós-Graduação em Ensino em Biociências e Saúde do Instituto Oswaldo Cruz/FIOCRUZ. https://orcid.org/0000-0001-9206-6004. E-mail: cristinadelou@gmail.com.
} 
and staying of target students of SE in the FI from 2015 to 2019. This is an exploratory research with a qualitative approach, in which information was collected to identify and characterize the target students of SE in all the 38 FI, through the Electronic System of the Citizen Information Service of the Federal Government. The data collected were explored through content analysis, which made it possible to verify that the FI, in general, has poorly organized data about target students of SE, uses poorly standardized nomenclatures and has expanded the target audience for the inclusion policy defined in the legislation. It was also observed that these students have, in their majority (69\%), physical, visual, or hearing impairment, and represent a very small portion of the student community. Despite the limitations, the present study highlights important issues for future research and may contribute to demonstrating the importance of student's data of SE for the improvement of school inclusion policies, especially in FI.

Keywords: Professional and Technological Education. Inclusive Education. School Census.

\section{Introdução}

Os estudantes público-alvo da Educação Especial (EE), aqueles com deficiências, transtornos globais do desenvolvimento e altas habilidades ou superdotação, conforme caracterizados na Política Nacional de Educação Especial na Perspectiva da Educação Inclusiva (BRASIL, 2008) e na Lei de Diretrizes e Bases da Educação Nacional (LDBEN) (BRASIL, 1996), têm ingressado nos mais diversos níveis e modalidades de ensino.

Tal movimento, verificado a partir de ações mundiais a favor da inclusão (UNESCO, 1990; 1994), obteve maior expressividade nos anos de 1990, ganhando força no Brasil, primeiramente, na Educação Básica e posteriormente no Ensino Superior e na Educação Profissional e Tecnológica (EPT). Tanto no Ensino Superior (SILVA; PAVÃO, 2019) quanto na EPT (PERTILE; MORI, 2018; SANTOS, 2020), o ingresso de estudantes público-alvo da EE tem se intensificado nos últimos anos em razão das políticas de inclusão educacional e, mais especificamente, a partir da implementação de ações afirmativas, que, de acordo com Mendes (2017), inicialmente se organizaram por meio de ações particulares de algumas instituições de ensino e, a partir de 2017, se deram por força de legislação.

O Governo Federal estabeleceu, em 2012, a reserva de 50\% das vagas das universidades federais e das instituições federais de ensino técnico de nível médio para o ingresso de alguns grupos minoritários, historicamente excluídos da educação formal/profissional, como estudantes de escola pública, de baixa renda, pretos, pardos e indígenas, acrescentando, em 2016, o grupo das pessoas com deficiência (BRASIL, 2012; 2016).

Assim, tem sido exigido das universidades e das instituições federais ofertantes de EPT, em especial dos Institutos Federais de Educação, Ciência e Tecnologia (IFs), foco do presente estudo, o ato constante de (re)pensar a cultura e as práticas escolares, no sentido de acolher e atender essa diversidade. Existem 38 IFs espalhados por todos os estados brasileiros e o Distrito Federal, compreendendo 599 unidades/campi que, em 2019, atuavam na formação de aproximadamente 950 mil estudantes matriculados, conforme dados disponibilizados pela Plataforma Nilo Peçanha (PNP) (BRASIL, 2020).

Ainda de acordo com a PNP (BRASIL, 2020), somente no ano de 2019, foram disponibilizadas 23.789 vagas para pessoas com deficiência nos IFs (aproximadamente $10 \%$ do total de vagas oferecidas nos editais de ingresso), sendo 16.881 vagas (71\%) para cursos técnicos de nível médio e 6.980 vagas $(29 \%)$ para curso de graduação, apresentando como critérios a associação da condição deficiência à escolarização em escola pública, em alguns casos, à renda e, em outros, à renda e à condição racial (preto, pardo ou indígena). 
Entretanto, observa-se que não são produzidos dados estatísticos oficiais sobre os estudantes público-alvo da EE matriculados nos IFs, tampouco na EPT, que indiquem quais as deficiências/condições desses estudantes, quais os índices de evasão e formação destes, entre outros dados de relevância para o planejamento e avaliação da política pública de inclusão educacional.

A inexistência de dados organizados e disponíveis, consistentes com o que se pratica na realidade da EPT, no Brasil, impossibilita esboçar um retrato fidedigno ou mesmo apresentar um panorama dessa modalidade de ensino, diferentemente do que se verifica para as demais modalidades de ensino regular, como a Educação Básica e Superior.

De acordo com estudo divulgado pelo Instituto Nacional de Estudos e Pesquisas Educacionais Anísio Teixeira (INEP) (MORAES; ALBUQUERQUE, 2019), os dados da EPT costumam ser extraídos do Censo Escolar da Educação Básica e do Censo da Educação Superior. Mas, tais Censos não abarcam a EPT em sua completude, não contabilizam, por exemplo, os estudantes ingressantes em cursos técnicos onde há ingresso no meio do ano, e estudantes de pós-graduação, modalidade que também está prevista na EPT.

Além disso, Moraes e Albuquerque (2019) ressaltam que existem diferenças metodológicas na forma de coleta de dados entre os respectivos Censos da Educação Básica e da Educação Superior, o que dificulta vislumbrar a EPT a partir do somatório de dados coletados em ambos os censos.

Diante desse cenário, a Secretaria de Educação Profissional e Tecnológica (SETEC) do Ministério da Educação (MEC) passou a organizar e publicar, a partir de 2018, algumas estatísticas oficiais da Rede de Educação Profissional, Científica e Tecnológica (Rede Federal $)^{3}$, através da PNP.

\begin{abstract}
A Plataforma Nilo Peçanha (PNP) é um ambiente virtual de coleta, validação e disseminação das estatísticas oficiais da Rede Federal de Educação, Profissional, Científica e Tecnológica (Rede Federal). Tem como objetivo reunir dados relativos ao corpo docente, discentes, técnico-administrativo e de gastos financeiros das unidades da Rede Federal, para fins de cálculo dos indicadores de gestão monitorados pela Secretaria de Educação Profissional e Tecnológica do Ministério da Educação SETEC/MEC. (BRASIL, 2018, p. 2).
\end{abstract}

Acredita-se que tal iniciativa tenha sido decorrente da necessidade de apresentar seus resultados para a sociedade, de prezar pela transparência pública, de produzir indicadores de gestão e de responder aos órgãos de controle.

Mas, apesar da PNP representar grande progresso para a Rede Federal, possibilitando avaliação ampla de suas ações, ainda carece de considerar questões relevantes para o direcionamento de programas e ações que visem à melhoria do atendimento aos estudantes da EPT. Em especial, destaca-se a ausência de dados sobre os estudantes público-alvo da EE. A PNP não apresenta dados estratificados sobre esses estudantes, apresenta a classificação dos estudantes apenas por critérios raciais, de renda familiar, sexo e faixa etária. (BRASIL, 2018; 2019 ; 2020).

\footnotetext{
3 A Rede Federal é composta por 38 Institutos Federais de Educação, Ciência e Tecnologia - IFs, 23 Escolas Técnicas Federais, 2 Centros Federais de Educação Tecnológica - CEFETs, 1 Universidade Tecnológica Federal e o Colégio Pedro II. No entanto, os IFs representam, aproximadamente, 92\% das matrículas na Rede Federal (BRASIL, 2020).
} 
Como uma proposta recente, era de se esperar que a PNP desse importância ao levantamento de dados desses estudantes, tendo em vista, principalmente, a existência e efetivação de política pública para reserva de vagas para as pessoas com deficiência (BRASIL, 2012; 2016) na Rede Federal e a necessidade de se acompanhar e avaliar como tem se dado o ingresso, a permanência e o êxito desse público de estudantes, que, por sua vez, requer ações específicas e especializadas.

Além disso, conforme afirmam Lima e Sousa (2014, p. 101), há de se considerar que "o fortalecimento de um sistema educacional pressupõe o conhecimento de dados educacionais voltados principalmente para formulação de políticas públicas e para o financiamento da educação".

Apesar de a Rede Federal não dispor de uma diretriz de âmbito nacional para orientar e subsidiar suas práticas inclusivas, os IFs, que representam grande parte da Rede Federal, aproximadamente 93\% das matrículas (BRASIL, 2020), têm se organizado para desenvolver ações a favor do ingresso e permanência dos estudantes público-alvo da EE, conforme evidenciam alguns registros de práticas inclusivas desenvolvidas em IFs (SANTOS; PONCIANO, 2019; PEROVANO, 2019; SANTOS, 2020) e demarca o estudo realizado por Mendes (2017), que objetivou conhecer as ações dos IFs para o atendimento ao público da EE.

\footnotetext{
A tese evidencia também que a organização das práticas de atendimento pedagógico e a estruturação dos núcleos de acessibilidade estão a depender das gestões locais em cada instituto, ou seja, diferentes movimentos estão se configurando dentro da rede federal e a interlocução entre essas instituições é quase inexistente no que se refere à Educação Especial. Sendo assim, perde-se a referência ao Programa/Ação Tecnep enquanto grupo gestor central no MEC e a Educação Especial passa a ter uma trajetória própria dentro de cada IF, sem carecer de programa, projeto, ação, campanha ou qualquer outra iniciativa nacional, tendo apenas a observância à legislação em vigor como diretriz. (MENDES, 2017, p. 9).
}

Nesse contexto, torna-se relevante conhecer quem compõe o público da EE nos IFs e qual sua representação no corpo estudantil dessas instituições, de tal forma que políticas e programas existentes, como as políticas de ações afirmativas e programas de atendimento a estudantes público-alvo da EE, possam ser avaliadas e novas ações possam ser implementadas visando à garantia do direito à educação de qualidade para o público em questão.

Assim, o trabalho investigativo apresentado se propõe a identificar e analisar os dados de acesso público sobre o ingresso e permanência de estudantes público-alvo da EE nos IFs do país, no período de 2015 a 2019.

\section{Metodologia}

O presente estudo se caracteriza como uma pesquisa do tipo exploratória (GIL, 2002), uma vez que pretende tornar o tema mais compreensível e explícito, possibilitando refletir e construir hipóteses sobre este, e possui abordagem qualitativa (MINAYO, 2015), na medida em que busca compreender uma determinada realidade social, recorrendo a dados quantitativos, sem, contudo, propor sua interpretação estatística, mas buscando refletir sobre seus significados, conforme indicam Minayo e Sanches (1993, p. 247): 
A relação entre quantitativo e qualitativo, entre objetividade e subjetividade não se reduz a um continuum, ela não pode ser pensada como oposição contraditória. Pelo contrário, é de se desejar que as relações sociais possam ser analisadas em seus aspectos mais "ecológicos" e "concretos" e aprofundadas em seus significados mais essenciais. Assim, o estudo quantitativo pode gerar questões para serem aprofundadas qualitativamente, e vice-versa.

Como instrumento de coleta de dados, foi utilizado um sistema eletrônico web, do Poder Executivo Federal: o Sistema Eletrônico do Serviço de Informação ao Cidadão (e-Sic ${ }^{4}$, que tem como propósito facilitar o acesso dos cidadãos às informações públicas, de acordo com o previsto na Lei de Acesso à Informação (BRASIL, 2011b).

Foram consultados cada um dos 38 IFs existentes no Brasil (BRASIL, 2020), no período de novembro de 2019 a março de 2020, através de abertura de processo no e-Sic, solicitando informações sobre o quantitativo de estudantes público-alvo da EE ingressantes, evadidos e concluintes no período de 2015 a 2019.

Os dados coletados foram sistematicamente organizados, possibilitando a realização de pré-análise, que se seguiu da análise mais específica dos elementos identificados como mais comuns, possibilitando a nomeação de categorias e subcategorias temáticas para a exploração do material coletado por meio da análise de conteúdo de Bardin (1977).

\section{Resultados e discussão}

A partir da exploração dos materiais coletados, foi possível definir duas categorias temáticas que direcionam o presente trabalho (Quadro 1). Tais categorias foram propostas para contemplar e organizar outras subcategorias que foram sendo constatadas por meio do reconhecimento de conteúdos mais comuns e relevantes nos materiais disponibilizados pelos IFs.

Quadro 1 - Categorias de análise

\begin{tabular}{|l|l|}
\hline \multirow{2}{*}{ CATEGORIAS TEMÁTICAS } & SUBCATEGORIAS/QUESTÕES DE ANÁLISE \\
\hline \multirow{2}{*}{$\begin{array}{l}\text { Dados sobre estudantes público- } \\
\text { alvo da EE nos IFs }\end{array}$} & Existem dados públicos e organizados? \\
\cline { 2 - 2 } $\begin{array}{l}\text { Caracterização dos estudantes } \\
\text { público-alvo da EE nos IFs }\end{array}$ & $\begin{array}{l}\text { Quais tipos de deficiências ou outras necessidades mais comuns } \\
\text { observadas entres os estudantes? }\end{array}$ \\
\cline { 2 - 2 } & $\begin{array}{l}\text { Existem semelhanças/diferenças desse público em outros } \\
\text { níveis/modalidades de ensino? }\end{array}$ \\
\hline
\end{tabular}

Fonte: Elaborado pelas autoras (2020).

\footnotetext{
${ }^{4}$ Este sistema objetiva organizar e facilitar o procedimento de acesso à informação, tanto para o cidadão quanto para a Administração Pública. Ele permite que qualquer pessoa, física ou jurídica, encaminhe pedidos de acesso à informação para órgãos e entidades do Executivo Federal, acompanhe o prazo e receba a resposta da solicitação. O cidadão ainda pode entrar com recursos e apresentar reclamações sem burocracia. Constitui-se num sistema de uso obrigatório, gerenciado pela CGU, a ser utilizado por todos os órgãos e entidades do Executivo Federal para o recebimento de requerimentos de acesso à informação, conforme a Portaria Interministerial n. 1.254/2015. O acesso ao sistema é realizado por meio, da página: http://www.acessoainformacao.gov.br/
} 
As subcategorias indicadas, apresentadas na forma de questões de análise, possibilitam melhor direcionamento das análises e discussões empreendidas no estudo, uma vez que se busca respondê-las.

\subsection{A disponibilidade de dados relativos aos estudantes público-alvo da EE nos IFs}

A busca de dados disponíveis sobre os estudantes com deficiência ou outras condições específicas, ingressantes e concluintes de cursos nos IFs evidenciou uma falta de organização de dados sobre estudantes público-alvo da EE pelas instituições de ensino. Em sua maioria, os IFs demonstraram não ter os dados solicitados de forma compilada e organizada.

Os IFs revelaram, com algumas exceções, não disporem de um sistema geral de gerenciamento de dados acadêmicos ou, pelo menos, de um sistema que considere os estudantes público-alvo da EE como um público específico, que deve ser, particularmente, caracterizado, uma vez que possui necessidades específicas que precisam ser reconhecidas, atendidas e acompanhadas pela instituição.

Muitas instituições pesquisadas disponibilizaram dados estratificados por campus, apresentados em formatos diferenciados e conteúdos pouco padronizados, inclusive quanto às nomenclaturas adotadas para fazer referência às condições de estudantes público-alvo da EE, mostrando a pouca sistematização interna desses dados, o que fica ainda mais evidente na comparação entre diferentes IFs.

Em estudo realizado em três universidades públicas para mapeamento e análise da matrícula de estudantes com deficiência, observou-se situações similares, tais como a identificação de "[...] procedimentos variados e muitas vezes ainda não sistematizados para localizar os estudantes com deficiência" e a percepção de "[...] uma diferença no uso de categorização (nomenclatura) das deficiências nos mapeamentos de uma universidade para outra" (MARTINS; LEITE; CIANTELLI, 2018, p. 20).

Coaduna com essas observações o registro feito em estudo realizado em um IF específico, no qual se procedeu o levantamento dos alunos público-alvo da EE atendidos pela instituição e "constatou-se a falta de um registro efetivo sobre o quantitativo de egresso" (SILVA; ROSA; SILVA, 2018, p. 9), demonstrando uma fragilidade no registro de acompanhamento desses estudantes.

Pressupõe-se que tais condições possam ser reflexo da ausência de uma política e/ou programa governamental destinado a este público específico da Rede Federal, uma vez que o contrário, provavelmente, demandaria o levantamento e um maior controle dos dados dos estudantes público-alvo da EE matriculados nos IFs e demais instituições que compõem a Rede, inclusive com caracterização desse público em levantamento de Censo Escolar, como na PNP.

Nessa perspectiva, Lima e Sousa (2014, p. 99) destacam a utilidade do Censo Escolar da Educação Básica para o desenvolvimento das políticas públicas educacionais:

No que tange a elaboração de políticas públicas, os dados levantados subsidiam a elaboração de diagnóstico educacional do Brasil, com objetivo de criar estratégias para acesso e permanência e o sucesso dos alunos na escola. O Censo também é responsável por fornecer dados necessários para o cálculo de indicadores educacionais. 
O Censo da Educação Básica contempla a identificação e a caracterização dos estudantes público-alvo da EE, cabendo às escolas a organização desses dados. Essa ação adquire maior relevância visto que há possibilidade de cômputo duplo de matrícula dos estudantes público-alvo da EE, em razão do Atendimento Educacional Especializado (AEE) ofertado (BRASIL, 2011a), o que implica na obtenção, pela escola, de mais recursos junto ao Fundo de Manutenção e Desenvolvimento da Educação Básica e de Valorização do Profissionais da Educação (FUNDEB).

Assim, às escolas de educação básica incumbe maior responsabilidade na manutenção e organização das informações sobre estudantes público-alvo da EE, já que servem de amparo para a política de educação inclusiva e seu financiamento. Diferentemente do que ocorre com os IFs, para os quais não há política nem financiamento específico para a educação inclusiva e os dados oficiais dispostos na PNP não qualificam os estudantes público-alvo da EE.

Por outro lado, mesmo que o Censo da Educação Básica faça o levantamento das informações dos estudantes público-alvo da EE e que tais informações sejam relevantes para as escolas, parece haver ainda algumas dificuldades na compreensão, pelas escolas, dos conceitos adotados no Censo. Sobre esse aspecto, foi publicado recentemente pelo INEP um Glossário da Educação Especial com o objetivo de apresentar uma definição dos conceitos adotados no sistema de coleta de informações, Educacenso, com vistas a facilitar a declaração das informações pelas escolas e assegurar a qualidade dos dados declarados (INEP, 2020b).

Nesse sentido, parece premente e geral a necessidade de produzir dados seguros sobre os estudantes público-alvo da EE dos diversos níveis de ensino, de modo que demonstrem a real situação de inclusão escolar no Brasil e amparem as propostas de melhorias nesse campo.

\subsection{A caracterização dos estudantes público-alvo da EE nos IFs}

Dentre os 38 IFs pesquisados, 21 (55\%) IFs $^{5}$ informaram todos os dados solicitados sobre o quantitativo de estudantes público-alvo da EE ingressantes, desistentes e concluintes no período de 2015 a 2019 (Figura 1).

Responderam parcialmente às informações solicitadas $14(37 \%) \mathrm{IFs}^{6}$, enquanto outros $3(8 \%)$ IFs $^{7}$ não informaram nenhum dado a respeito, inclusive alguns justificaram não possuírem os dados compilados (Figura 1).

\footnotetext{
${ }^{5}$ IFs que informaram dados completos (contemplando todos os campi, o período delimitado e o tipo de informação): IFAC, IFAL, IFAM, IFAP, IFC, IFCE, IFES, IFFARR, IFG, IFMS, IFNMG, IFPE, IFPI, IFPR, IFRJ, IFRN, IFS, IFSC, IFSP, IFSUL, IFTM.

\begin{abstract}
${ }^{6}$ IFs que informaram dados parciais: IFB (informou dados de 19 dos seus 10 campi); IFBA (informou dados de 16 dos seus 22 campi); IFF (informou dados de 9 dos seus 14 campi); IFMA (informou dados de 27 dos seus 29 campi); IFMT (informou dados de 14 dos seus 19 campi); IFRO (informou dados de 9 dos seus 10 campi); IFRR (informou dados de 4 dos seus 5 campi); IFRS (informou dados de 12 dos seus 17 campi); IFSERTÃO-PE (informou dados de 3 dos seus 7 campi); IFSUDESTEMG (informou dados de 6 dos seus 10 campi); IFTO e IFGOIANO (informaram apenas dados de ingresso); IFPB (informou apenas dados de ingresso de 18 dos seus 22 campi); IFPA (informou dados apenas de ingresso, de 2018 e 2019, de 16 dos seus 19 campi).
\end{abstract}

${ }^{7}$ IFs que não informaram nenhum dado: IFBAIANO, IFMG e IFSULDEMINAS. 
Figura 1 - Quantitativo de IFs que informaram os dados de estudantes público-alvo da EE

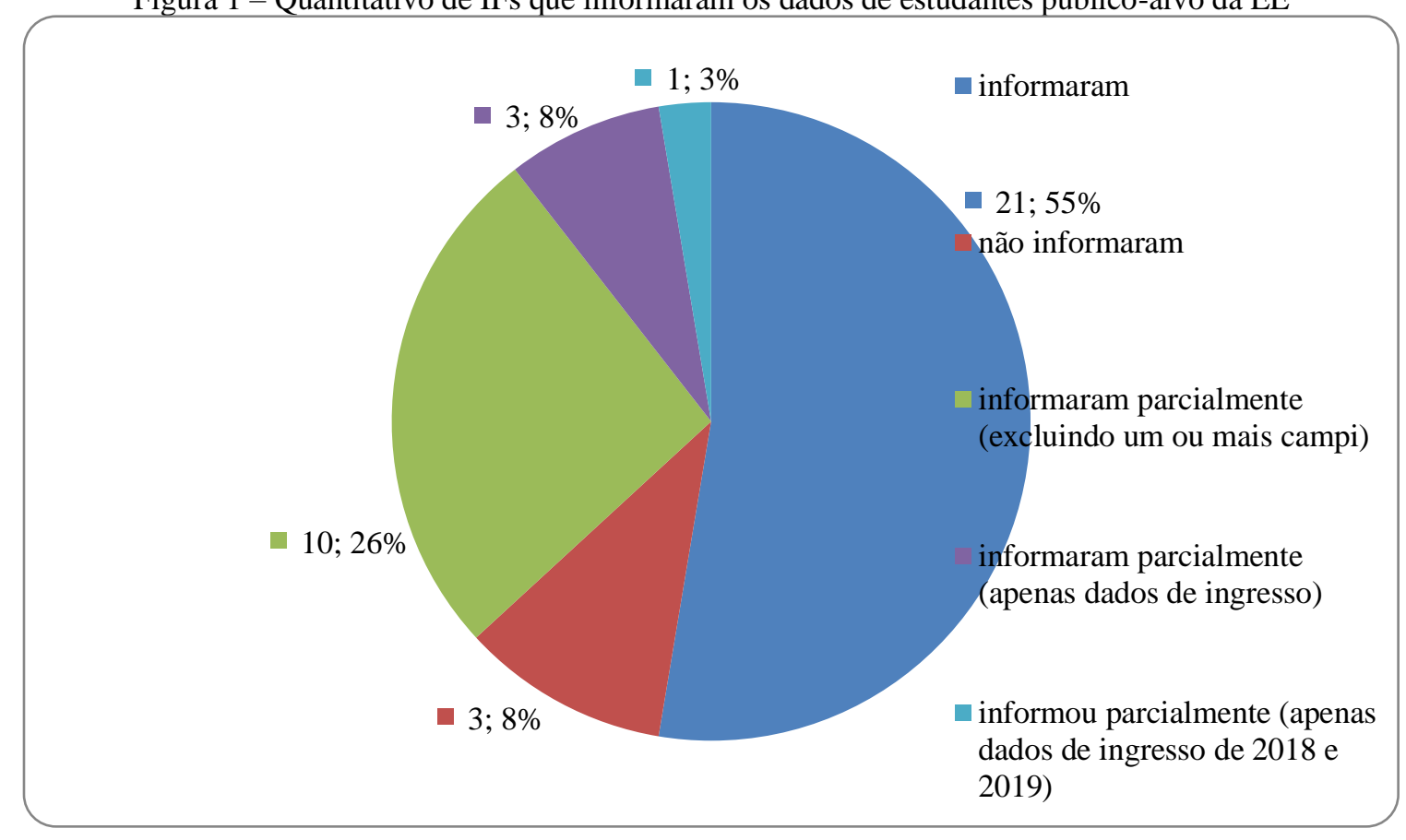

Fonte: Elaborado pelas autoras (2020).

Considerando as informações disponibilizadas sobre ingresso de estudantes públicoalvo da EE por 35 (92\%) IFs (63\% que informaram dados completos de ingresso e $29 \%$ que informaram dados incompletos de ingresso, não contemplando todos os campi ou todos os anos delimitados), pode-se constatar que, no período de 2015 a 2019, ingressaram aproximadamente 8.676 estudantes com alguma deficiência ou outra necessidade específica nos IFs. O que representaria, aproximadamente, $2,07 \%$ do ingresso geral de estudantes verificado nos IFs apenas no último ano (2019), e 0,77\% do ingresso total de estudantes dos últimos três anos, os quais se tem registro pela PNP. (BRASIL, 2018; 2019; 2020).

Nesse raciocínio, mesmo sem dispor de dados da PNP relativos ao ingresso geral de estudantes nos IFs nos anos de 2015 e 2016, podemos deduzir que os estudantes público-alvo da EE representaram menos de 1\% das matrículas efetivas dos IFs entre 2015 e 2019.

Situação similar à que vem sendo verificada nas instituições públicas de Ensino Superior, onde o percentual de estudantes público-alvo da EE matriculados também tem representado menos de $1 \%$ das matrículas totais, aproximadamente $0,80 \%$ do total de matrículas em cursos de graduação presenciais e a distância, de acordo com os Censos da Educação Superior de 2015 e de 2018 (INEP, 2016; 2019b).

Todavia, na comparação do quantitativo de estudantes público-alvo da EE ingressantes nos IFs nos últimos cinco anos, aproximadamente 8.676 estudantes, com o número de vagas disponibilizadas para ingresso de pessoas com deficiência nos IFs somente no ano de 2019, 23.789 vagas (BRASIL, 2020), observa-se uma discrepância bastante significativa.

Assim, o total aproximado de ingresso de estudantes público-alvo da EE verificado nos IFs nos últimos cinco anos representa 36,5\% do total de vagas reservadas para o ingresso desse público em apenas um ano.

Há que se considerar que a reserva de vagas para pessoas com deficiência se estabeleceu a partir de meados de 2017, já que sua prescrição na Lei de Cotas ocorreu apenas no final de 
2016 (BRASIL, 2016). Inclusive, a PNP não apresenta dados de reserva de vagas referentes aos anos de 2017 e 2018, apenas em 2019 acrescentou um item (5.b) relativo à reserva de vagas efetuadas na Rede Federal.

Além disso, conforme indicado na introdução deste estudo, a reserva de vagas nos IFs é feita tanto para a graduação como para cursos técnicos de nível médio e segue os critérios estabelecidos na Lei de Cotas (BRASIL, 2012; 2016), associando a condição de defíciência à escolarização em escola pública, em alguns casos à renda e em outros à renda e à condição racial. Deve-se considerar que essas associações podem subdividir as vagas destinadas a esse público, restringindo o acesso a pessoas com deficiência que se enquadrem concomitantemente em outras especificidades.

Outra questão a se considerar é se os IFs contabilizam como estudantes público-alvo da EE aqueles que, mesmo ingressando pela reserva de vagas e possuindo condição que se enquadre nesse público, não demandem atendimento especializado da instituição.

Trata-se de um dado significativo que merece uma análise mais aprofundada e, apesar de não constituir objetivo principal deste estudo, acaba por justificar sua intenção de identificar e caracterizar os estudantes público-alvo da EE dos IFs, na medida em que possibilita novas reflexões sobre as políticas públicas de atendimento a essa parcela de estudantes.

Para a caracterização do público da EE dos IFs de forma mais contundente, propõe-se um recorte dos dados recolhidos, considerando apenas os 21 (55\%) IFs que disponibilizaram informações completas sobre os estudantes público-alvo da EE.

Assim, na Tabela 1, são apresentados os quantitativos de estudantes de cursos ofertados pelos IFs, nos últimos cinco anos, por tipo de deficiência/condição, com apontamento das situações de ingressantes, desistentes, jubilados ou concluintes.

Tabela 1 - Dados estudantes público-alvo da EE dos IFs (período 2015 a 2019)

\begin{tabular}{lcccc}
\hline \multicolumn{1}{c}{$\begin{array}{c}\text { DEFICIÊNCIA/ } \\
\text { CONDIÇÃ. }\end{array}$} & $\begin{array}{c}\text { QUUANT. } \\
\text { INGRESSANTE }\end{array}$ & $\begin{array}{c}\text { TRANCAMENTO } \\
\text { DESISTENTE } \\
\text { TRANSFERIDO }\end{array}$ & $\begin{array}{c}\text { QUANT. } \\
\text { JUBILADO }\end{array}$ & $\begin{array}{c}\text { QUANT. } \\
\text { CONCLUINTE }\end{array}$ \\
\hline $\begin{array}{l}\text { Altas habilidades ou } \\
\text { superdotação }\end{array}$ & 108 & 23 & 0 & 29 \\
\hline Auditiva & 1013 & 544 & 0 & 0 \\
\hline Esquizofrenia & 16 & 1 & 0 & 284 \\
\hline Física & 1603 & 655 & 4 & 66 \\
\hline Intelectual & 378 & 92 & 1 & 49 \\
\hline Múltipla & 272 & 66 & 0 & 185 \\
\hline Não especificada & 314 & 274 & 0 & 42 \\
\hline Outras & 185 & 48 & 0 & 4 \\
\hline Paralisia cerebral & 22 & 3 & 0 & \\
\hline
\end{tabular}




\begin{tabular}{lcccc}
\hline Síndrome de Asperger & 49 & 8 & 0 & 4 \\
$\begin{array}{l}\text { Síndromes ou doenças } \\
\text { raras }\end{array}$ & 21 & 3 & 0 & 2 \\
$\begin{array}{l}\text { Surdocegueira } \\
\begin{array}{l}\text { Transtorno do Espectro } \\
\text { Autista }\end{array}\end{array}$ & 2 & 1 & 0 & 0 \\
$\begin{array}{l}\text { Transtornos globais do } \\
\text { desenvolvimento }\end{array}$ & 50 & 16 & 0 & 19 \\
$\begin{array}{l}\text { Transtornos funcionais } \\
\text { específicos }\end{array}$ & 224 & 12 & 0 & 2 \\
$\begin{array}{l}\text { Visual } \\
\text { TOTAL }\end{array}$ & 1403 & 27 & 0 & 21 \\
\hline
\end{tabular}

Fonte: Elaborado pelas autoras (2020).

A coleta de dados junto aos IFs evidenciou uma ampliação do público da EE. É notória a inexistência de uma padronização desse público, inclusive com relação às nomenclaturas apresentadas, e que os estudantes público-alvo da EE considerados pelos IFs não se restringem à definição da legislação educacional vigente (BRASIL, 1996; 2008).

À definição da LDBEN são adicionadas diversas outras condições específicas que requerem dos IFs um atendimento diferenciado, como a dificuldade de aprendizagem, os transtornos mentais/psiquiátricos, as doenças neurológicas e os transtornos funcionais específicos. Fato que, conforme estudo de Martins, Leite e Ciantelli (2018), também tem ocorrido em algumas universidades públicas, o que provoca a reflexão sobre a abrangência do público da EE definido pela legislação.

Nessa perspectiva, para efeitos de análise, foram apresentados como estudantes públicoalvo da $\mathrm{EE}$ todos aqueles indicados pelos IFs, não se restringindo à definição da LDBEN apresentada inicialmente.

Assim, a partir dos dados coletados, foram organizadas as seguintes classificações de estudantes público-alvo da EE, por meio do agrupamento de alguns tipos e nomenclaturas de deficiência/condição identificados:

a) Deficiência auditiva: perdas auditivas e surdez;

b) Deficiência visual: perdas visuais e cegueira;

c) Deficiência intelectual: retardo mental leve, moderado ou elevado, déficit cognitivo, deficiência mental;

d) Deficiência múltipla: apresenta mais de uma deficiência ou condição, independentemente de quais sejam;

e) Síndromes ou doenças raras: Tetralogia de Fallot, Hidrocefalia, Síndrome de West, Esclerose Múltipla, Síndrome de Turner, Ataxia de Friedreich, Síndrome de Williams, Síndrome de Down, Paralisia Infantil, Síndrome de Tourette, Uveíte, Síndrome de Guillain-Barré, Transtorno Desintegrativo da Infância, Síndrome de Írlen;

f) Transtornos funcionais específicos: Déficit de Atenção (DA), Transtorno do Déficit de Atenção (TDA), Transtorno do Déficit de Atenção e Hiperatividade (TDAH), Dislexia, Discalculia, Transtorno Desafiador de Oposição (TOD), Transtorno Obsessivo Compulsivo (TOC), Transtorno de Aprendizagem (TA), Transtorno de Ansiedade Generalizada (TAG), Distúrbio do Processamento Auditivo Central (DPAC); 


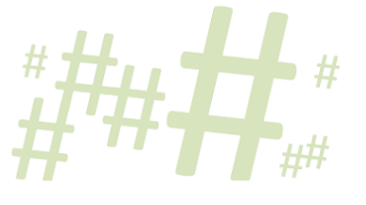

g) Outras: Dificuldade de Aprendizagem, condutas típicas, transtorno mentais/psiquiátricos, doenças neurológicas;

h) Não especificada: deficiência/condição não informada.

Analisando os dados, constata-se que há maior incidência de estudantes com deficiência física, seguido de deficiência visual e deficiência auditiva. Essas três condições somadas representam $69 \%$ do total de estudantes público-alvo da EE ingressantes nos IFs.

Tal constatação coincide com as informações de ingresso de estudantes público-alvo da EE em instituições públicas de ensino superior. Dados do Censo da Educação Superior de 2018 apontam que, entre os estudantes com deficiência matriculados em cursos de graduação, as deficiências físicas são as mais frequentes, seguidas da baixa visão, deficiência auditiva, cegueira, deficiência intelectual e surdez. Sendo que a soma das três condições mais frequentes representa 79\% do total de alunos público-alvo da EE matriculados (INEP, 2019b).

Por outro lado, na Educação Básica, os estudantes que apresentam deficiência intelectual são, historicamente, o público que mais é matriculado em classes comuns, o que vem representando um quantitativo crescente e expressivo dos estudantes público-alvo da EE. De acordo com os Censos Escolares da Educação Básica de 2018 e de 2019, os estudantes com deficiência intelectual têm representado $65 \%$ de todo o público da EE matriculado na Educação Básica (INEP, 2019a; 2020a).

Nos IFs, a deficiência intelectual e a deficiência múltipla, condições para as quais a Terminalidade Específica (TE) está assegurada na legislação educacional (BRASIL, 1996; 2001; 2001a), ocupam a quarta e a sexta posição, respectivamente, em um escalonamento decrescente do quantitativo de estudantes ingressantes. Assim, os estudantes para os quais, legalmente, deve ser analisada a necessidade de adoção da TE constituem $11 \%$ do total de estudantes público-alvo da EE ingressantes no IFs.

Infere-se que talvez pelo fato de a TE servir a um percentual pouco representativo dentre o total de estudantes público-alvo da EE ingressantes nos IFs, não se apresente ainda em muitas regulamentações dos IFs, conforme demonstram estudos recentes (PERTILE; MORI, 2018; SANTOS, 2019; OLIVEIRA; DELOU, 2020).

Outra observação sobre os dados em análise (Tabela 1), e que chama a atenção, é o quantitativo de estudantes desistentes ou em situação de trancamento ou transferência em relação ao quantitativo de ingressantes. O número de estudantes público-alvo da EE desistentes representa quase $40 \%$ do montante de estudantes público-alvo da EE ingressantes em um mesmo período.

Tal constatação induz diversos questionamentos sobre quais fatores devem estar favorecendo esse cenário, os quais não constituem foco do presente estudo, mas, novamente, evidenciam a importância de se dispor de dados organizados relativos aos estudantes públicoalvo da EE nos IFs para subsidiar políticas e/ou programas que favoreçam a permanência e êxito desses estudantes.

Outras implicações podem ser adicionadas a essa reflexão na medida em que se pode questionar em que contexto têm ocorrido as transferências de estudantes público-alvo da EE: será por solicitação e interesse do próprio estudante? Ou por encaminhamento da instituição?

Quanto aos concluintes, é mais difícil fazer alguma reflexão sobre sua representatividade, uma vez que seria necessário considerar as durações dos cursos, além das possíveis flexibilizações de tempo previstas para o atendimento aos estudantes público-alvo da EE. 
Além disso, outro dado que instiga alguns questionamentos é relativo ao jubilamento, que, inclusive, na solicitação de dados não havia sido mencionado, mas apareceu nas respostas de dois IFs que registraram juntos o jubilamento de sete estudantes público-alvo da EE.

Tendo em vista as garantias de flexibilização temporal para o atendimento aos estudantes público-alvo da EE (BRASIL, 1996; 2008; 2015) e considerando que os critérios de jubilamento de estudantes público-alvo da EE têm sido estabelecidos pelas próprias instituições de ensino, já que a política pública de inclusão educacional não trata desse tema em específico, ficam os questionamentos de como se deram tais processos de jubilamento: se foram garantidas as adaptações razoáveis (BRASIL, 2015) necessárias para participação e desenvolvimento destes estudantes nos seus respectivos cursos, e se a prática do jubilamento realmente deve ser considerada para os estudantes em questão.

Percebe-se que muitas das questões aqui apontadas, e outras mais, poderiam estar sendo evidenciadas a partir da organização dos dados de estudantes público-alvo da EE da EPT, da Rede Federal e dos IFs, fomentando a realização de investigações, avaliações e discussões relevantes sobre o atendimento, de direto, desse público.

Daí decorre a necessidade apontada por Martins, Leite e Ciantelli (2018, p. 21), fazendo referência a instituições públicas de educação superior, mas que, sem dúvida, também se aplica aos IFs:

[...] faz-se necessário que as instituições invistam na criação de procedimentos acadêmicos que permitam identificar semestralmente quem são esses estudantes, em que cursos estão matriculados, qual a sua deficiência e quais são as adaptações e os ajustes educacionais desejáveis para o desenvolvimento acadêmico nos contextos investigados.

Nesse sentido, a organização e disponibilização desses dados facilitaria a implementação de acompanhamento e avaliação das ações de inclusão nos IFs e, de forma centralizada e articulada, poderia contribuir para orientar e incentivar o desenvolvimento de práticas inclusivas em toda a Rede Federal.

\section{Considerações finais}

De modo geral, foi possível perceber que os IFs têm organizado os dados relativos as estudantes público-alvo da EE de forma pouco sistematizada, o que se acredita ser decorrente de diversos fatores, entre eles: a ausência de um censo da EPT e/ou da Rede Federal que exija a identificação desses estudantes dentre os demais e a ausência de programas ou políticas específicas da Rede Federal que orientem as ações dos IFs, propondo certa padronização dessas informações e, dentro das possibilidades, especificando recursos para atendimento desse público.

Constatou-se ainda que, para além da dificuldade na sistematização dos dados por parte dos IFs, outras questões influenciam na obtenção de informações para caracterização dos estudantes público-alvo da EE, as quais também ocorrem em algumas universidades públicas (MARTINS; LEITE; CIANTELLI, 2018), como a falta de padronização de nomenclaturas adotadas por cada instituição de ensino e a ampliação do público da EE definido na LDBEN.

Os estudantes público-alvo da EE que têm ingressado nos IFs nos últimos cinco anos (2015 a 2019) ainda representam uma parcela muito pequena da comunidade estudantil, não chegando a representar $1 \%$ do total de estudantes. Em sua maioria (69\%) apresentam 
deficiência física, visual, ou auditiva constituindo um perfil similar ao público da EE da educação superior (INEP, 2019b), mas bem diferente da Educação Básica, onde predominam as condições de deficiência intelectual, Transtorno do Espectro Autista (TEA) e deficiência física (INEP, 2019a; 2020a).

Apesar das limitações do presente estudo, principalmente relativas à impossibilidade de apresentar um retrato fiel do quantitativo e do perfil dos estudantes público-alvo da EE dos IFs, decorrentes da dificuldade de se obter informações completas e precisas dos IFs, foi possível identificar questões relevantes que poderão orientar investigações futuras, como a discrepância entre a reserva de vagas para pessoas com deficiência e seu ingresso nos IFs e o representativo número de desistências, trancamentos ou transferências de estudantes público-alvo da $\mathrm{EE}$ dos IFs.

Todavia, ressalta-se a relevância da organização de tais dados para o direcionamento ações de atendimento escolar dos estudantes público-alvo da EE para reivindicar recursos técnicos e financeiros de apoio ao atendimento, além de servir de avaliação e orientação para as políticas da própria instituição. Nessa perspectiva, constitui um bom exemplo a situação atual de Pandemia da Covid-19, quando os IFs que estão oferecendo o ensino de forma remota, ou mesmo a SETEC/MEC, necessitariam dispor, de antemão, de um panorama das especificidades de estudantes público-alvo da EE matriculados, de modo a considerá-los nas novas proposta e formatos de ensino para que estas sejam o mais inclusivas possível.

\section{Referências}

BARDIN, Laurence. Análise de Conteúdo. Lisboa: Editora 70, 1977.

BRASIL. Lei no 9.394, de 20 de dezembro de 1996. Lei de Diretrizes e Bases da Educação Nacional. Brasília, DF: MEC, 1996.

BRASIL. Parecer CNE/CBE $\mathbf{n}^{\mathbf{0}}$ 17/2001. Diretrizes Nacionais para a Educação Especial na Educação Básica. Brasília, DF: MEC, 2001a.

BRASIL. Resolução CNE/CBE nº. 2/2001. Institui Diretrizes Nacionais para a Educação Especial na Educação Básica. Brasília, DF: MEC, 2001 b.

BRASIL. Política Nacional da Educação Especial na Perspectiva da Educação Inclusiva. Brasília, DF: MEC, 2008.

BRASIL. Decreto $\mathbf{n}^{0}$ 7.611, de 17 de novembro de 2011. Dispõe sobre a educação especial, o atendimento educacional especializado e dá outras providências. Brasília, DF, 2011a.

BRASIL. Lei $\mathbf{n}^{\circ}$ 12.527, de 18 de novembro de 2011. Regula o acesso a informações previsto na Constituição Federal; altera a Lei no 8.112, de 11 de dezembro de 1990; revoga a Lei no 11.111, de 5 de maio de 2005, e dispositivos da Lei no 8.159, de 8 de janeiro de 1991; e dá outras providências. Brasília, DF: MEC, 2011b.

BRASIL. Lei $\mathbf{n}^{\mathbf{0}}$ 12.711, de 29 de agosto de 2012. Dispõe sobre o ingresso nas universidades federais e nas instituições federais de ensino técnico de nível médio e dá outras providências. Brasília, DF: MEC, 2012. 
BRASIL. Lei $\mathbf{N}^{\mathbf{0}}$. 13.146, de 6 de julho de 2015. Institui a Lei Brasileira de Inclusão das Pessoas com Deficiência (Estatuto da Pessoa com Deficiência). Brasília, DF: MEC, 2015.

BRASIL. Lei $\mathbf{n}^{\circ}$ 13.409, de 28 de dezembro de 2016. Altera a Lei $n^{\circ} 12.711$, de 29 de agosto de 2012, para dispor sobre a reserva de vagas para pessoas com deficiência nos cursos técnico de nível médio e superior das instituições federais de ensino. Brasília, DF: MEC, 2016.

BRASIL. Plataforma Nilo Peçanha. Brasília, DF, 2018. Disponível em: http://plataformanilopecanha.mec.gov.br/2018.html. Acesso em: 14 jun. 2020.

BRASIL. Plataforma Nilo Peçanha. Brasília, DF, 2019. Disponível em: http://plataformanilopecanha.mec.gov.br/2019.html. Acesso em: 10 jul. 2020.

BRASIL. Plataforma Nilo Peçanha. Brasília, DF, 2020. Disponível em: http://plataformanilopecanha.mec.gov.br/2020.html. Acesso em: 21 ago. 2020.

GIL, Antonio Carlos. Como elaborar projetos de pesquisa. 4. ed. São Paulo: Atlas, 2002.

INEP. Sinopse Estatística da Educação Superior 2015. Brasília: Inep, 2016. Disponível em: http://portal.inep.gov.br/web/guest/sinopses-estatisticas-da-educacao-superior. Acesso em: 11 ago. 2020.

INEP. Sinopse Estatística da Educação Básica 2018. Brasília: Inep, 2019a. Disponível em: http://portal.inep.gov.br/web/guest/sinopses-estatisticas-da-educacao-basica. Acesso em: 11 ago. 2020.

INEP. Sinopse Estatística da Educação Superior 2018. Brasília: Inep, 2019b. Disponível em: http://portal.inep.gov.br/web/guest/sinopses-estatisticas-da-educacao-superior. Acesso em: 11 ago. 2020.

INEP. Sinopse Estatística da Educação Básica 2019. Brasília: Inep, 2020a. Disponível em: http://portal.inep.gov.br/web/guest/sinopses-estatisticas-da-educacao-basica. Acesso em: 11 ago. 2020.

INEP. Glossário da Educação Especial Censo Escolar 2020. Brasília: Inep, 2020b. Disponível em:

http://download.inep.gov.br/educacao_basica/censo_escolar/caderno_de_instrucoes/Glossario _da_Educacao_Especial_Censo_Escolar_2020.pdf. Acesso em: 12 ago. 2020.

LIMA, Angélica Acácia Ayres Angola; SOUSA, Fábio Pereira. Censo Escolar da Educação Básica: uma referência para elaboração de políticas públicas e transferência de recursos para educação pública. Revista Resumo Com Censo, v. 1, n. 1, p. 94-102, dez. 2014. Disponível em: http://periodicos.se.df.gov.br/index.php/comcenso/article/view/25. Acesso em: 18 jul. 2020.

MARTINS, Sandra Eli Sartoreto de Oliveira; LEITE, Lúcia Pereira; CIANTELLI, Ana Paula Camilo. Mapeamento e análise da matrícula de estudantes com deficiência em três Universidades públicas brasileiras. Revista Psicologia Escolar e Educacional, número 
especial, p. 15-23, 2018. Disponível em: https://www.scielo.br/scielo.php?pid=S1413$85572018000400015 \&$ script=sci_abstract\&tlng=pt. Acesso em: 21 jul. 2020.

MENDES, Katiuscia Aparecida Moreira de Oliveira. Educação Especial Inclusiva nos Institutos Federais de Educação, Ciência e Tecnologia Brasileiros. 2017. Tese (Doutorado em Educação) - Faculdade de Educação da Universidade Federal de Goiás, Goiânia, 04 dez. 2017.

MINAYO, Maria Cecília de Souza; SANCHES, Odécio. Quantitativo-qualitativo: oposição ou complementaridade? Cadernos de Saúde Pública, Rio de Janeiro, v. 9, n. 3, p. 239-262, jul./set.1993. Disponível em: https://www.scielo.br/scielo.php?pid=0102311X19930003\&script=sci_issuetoc. Acesso em: 06 jun. 2020.

MINAYO, Maria Cecília de Souza (org.). Pesquisa social: teoria, método e criatividade. 34. ed. Petrópolis, RJ: Vozes, 2015.

MORAES, Gustavo Henrique; ALBUQUERQUE, Ana Elizabeth M. de. As Estatísticas da Educação Profissional e Tecnológica: silêncios entre os números da formação de trabalhadores. Brasília: INEP, 2019. Disponível em: http://portal.inep.gov.br/informacao-dapublicacao/-/asset_publisher/6JYIsGMAMkW1/document/id/6688378. Acesso em: 08 jul. 2020 .

OLIVEIRA, Wanessa Moreira; DELOU, Cristina Maria Carvalho. Terminalidade Específica nos Institutos Federais: um panorama. Revista Educação Especial, Santa Maria, v. 33, p. 136, 2020. Disponível em:

https://periodicos.ufsm.br/educacaoespecial/article/view/48006/html. Acesso em: 30 set. 2020.

PEROVANO, Laís Perpetuo (org.). Práticas Inclusivas no Ensino Técnico. Campos dos Goytacazes, RJ: Brasil Multicultural, 2019. 172p.

PERTILE, Eliane Brunetto; MORI, Nerli Nonato Ribeiro. Institutos Federais de Educação: as discussões sobre a terminalidade específica e a necessidade do atendimento educacional especializado. Revista Teoria e Prática da Educação, Maringá, v. 21, n. 1, jan./abril, 2018. Disponível em: http://ojs.uem.br/ojs/index.php/TeorPratEduc/article/view/45228. Acesso em: jan. 2020.

SANTOS, Juliani Natalia dos; PONCIANO, Paola Cavalheiro (org.). Educação Inclusiva Sob Múltiplos Olhares: ações na Educação Profissional e Tecnológica. 1 ed. Jundiaí, SP: Paco, 2019. 116p.

SANTOS, Thamille Pereira. Certificação por Terminalidade Específica na Rede Federal de Educação Profissional, Científica e Tecnológica: produto e produtora de representações culturais. 2019. Dissertação (Mestrado Profissional em Educação Profissional e Tecnológica), Programa de Pós-Graduação em Educação Profissional e Tecnológica - Instituto Federal Farroupilha- Polo Jaguari, Santa Maria/RS, 2019.

SANTOS, Jessica Rodrigues. Inclusão Escolar e os Modos de Planejamento Educacional Individualizado nos Institutos Federais Brasileiros. 2020. Dissertação (Mestrado em 
Educação Especial) - Programa de Pós-Graduação em Educação Especial do Centro de Educação e Ciências Humanas da Universidade Federal de São Carlos, São Carlos/SP, 2020.

SILVA, Lamara Fabia Lucena; ROSA, Mariana Camilo Medeiros; SILVA, Rivânia de Sousa. Inclusão de discentes com deficiência: dimensionamento sobre a política de acesso e permanência nos campi do Instituto Federal de Educação, Ciência e Tecnologia da Paraíba IFPB. In: COLÓQUIO LUSO-BRASILEIRO DE EDUCAÇÃO: CURRÍCULO, INCLUSÃO E EDUCAÇÃO ESCOLAR, 4., 2018, Braga e Paredes de Coura. Anais [...]. Braga e Paredes de Coura, 2018. p. 1-11. Disponível em:

https://www.revistas.udesc.br/index.php/colbeduca/issue/view/591. Acesso em: 18 jul. 2020.

SILVA, Mariane Carloto; PAVÃO, Sílvia Maria de Oliveira. Terminalidade específica para estudantes com deficiência na educação superior: práticas (a serem) implementadas? Revista Brasileira de Educação, Santa Maria, v. 24, dez. 2019. Disponível em:

https://www.scielo.br/scielo.php?pid=S1413-24782019000100241\&script=sci_arttext\&tlng=pt. Acesso em: 06 fev. 2020.

UNESCO. Declaração Mundial sobre Educação para Todos: plano de ação para satisfazer as necessidades básicas de aprendizagem. Jomtien/Tailândia: UNESCO, 1990.

UNESCO. Declaração de Salamanca: Sobre Princípios, Políticas e Práticas na Área das Necessidades Educativas Especiais. Salamanca-Espanha: UNESCO, 1994.

Recebido em janeiro de 2021.

Aprovado em maio de 2021. 